\title{
The Profile of Older Generation in Russia: Evidence from the Tomsk Region
}

\author{
Irina Pavlova* a , Ilya Gumennikov ${ }^{\mathrm{a}}$, Evgeny Monastyrny ${ }^{\mathrm{a}}$ \\ * Corresponding author: Irina Pavlova, iapav@mail.ru \\ a National Research Tomsk Polytechnic University, 30, Lenina Av., Tomsk, 634050, Russia, iapav@mail.ru, +7913841 6303
}

\begin{abstract}
http://dx.doi.org/10.15405/epsbs.2016.02.50

This research paper analyzes the existing forms of statistical surveys and indicators in Russia which could be associated with estimating the objective component of well-being of the elderly population. Also, it focused on identifying the possible statistics time depth for indicators evaluation in the study area. The article determines the scope of objective indicators in the Russian statistics and draws a profile on older people's quality of life in the Tomsk region for the period 2011-2014 on the bases of regional statistical data.
\end{abstract}

C) 2016 Published by Future Academy www.FutureAcademy.org.uk

Keywords: Elderly population, regional statistics, Russia, national statistics, well-being.

\section{Introduction}

The presented research addresses the analysis of the statistical data on both federal and regional levels in the Russian Federation and foreign statistical information, which is available at the end of 2014. We aim to determine the scope of objective indicators, which help to describe the well-being of older generation in Russia. On the regional level, we assess the statistics for the Tomsk region (Tomsk Oblast) as a case study.

\section{Methodology and Research Findings}

As the main sources used for this study, we focus on numerous databases and documents of official governmental and public bodies such as the Department of Economic and Social Affairs of the United Nations Secretariat, United Nations Statistics Division Data Base, World Health Organization (Global Health Observatory Data Repository), Organization for Economic Co-operation and Development Data 
Base, Eurostat, Federal State Statistics Service (FSSS) of the Russian Federation (Section "Older generation"). The official statistics for Russia can be withdrawn on the basis of the List of Indicators from Federal Statistical Observation Forms (2014) and the List of Indicators submitted by the Tomsk Regional Statistics Service (Tomskstat) covering the issues of the well-being of the older generation in the report "Evaluation and improvement of the social, economic and emotional well-being of elderly people in 2000-2013" made on the basis of the selected indicators.

The research is also supported by the Federal laws and Regulations of the Government of the Russian Federation on collecting and processing statistical information; Policy Statements and Orders of the FSSS; the List and the Album of statistical observations forms (2014), etc.

Objective social and economic indicators of the well-being of the elderly population as a phenomenon can be researched and assessed with the reference to the data and approaches used for computation of international indices that cover different aspects related to the well-being of the elderly population. In order to evaluate older adults' well-being and their quality of life in Russia, as the first step for the development of the Russian statistical model we assess methodologies and data for two international indices such as the Active Ageing Index (AAI) and the Global AgeWatch Index (AW) including their data sources coverage and methodologies limitations.

The Global AgeWatch Index can be calculated for about 100 countries (Global AgeWatch Index 2014: Insight report, summary and methodology, 2014), however the problem of incomplete and imperfect data coverage still exists. Data gaps for the assessment from international databases were compensated with national statistics for a number of countries. Thus, the data collected are not methodologically unified due to different national data collection approaches. Furthermore, "homogeneity" of the index is weakened by integration into the methodology of some subjective indicators.

The Global AgeWatch Index includes four domains such as (1) Income security; (2) Health status; (3) Capability; (4) Enabling environment. The Active Ageing Index also includes four domains: (1) Employment; (2) Participation in society; (3) Independent, healthy and secure living; (4) Capacity for active ageing. This index was originally developed and calculated on the basis of significant academic research and extensive long-term complex supranational statistical surveys for 27 countries of the European Union (Zaidi et al, 2013). However, such homogeneity of data is challenged if the index is calculated for the increasing number of countries, especially non-European ones, since the issue of statistical data gaps will arise.

\section{Results}

Currently on the federal level of the Russian Federation, the FSSS has been collecting and processing statistical data ("Older Generation" Section of the Federal State Statistics Service of the Russian Federation), covering some well-being issues concerning the older generation of the Russian Federation. Data falls within the following domains (2014):

- Demographics;

- Pension benefits for senior citizens;

- Measures of social support for senior citizens; 
- Average monthly wages and number of employees with the distribution by age, gender and occupation;

- Economic activity, employment and unemployment;

- Use of information technology and public information and telecommunication networks;

- Social activity for senior citizens.

In order to research statistics on the well-being of the elderly population at the regional level in Tomsk region, the List (2014) and the Album of statistical observations forms (2014) were analyzed as the main documents of methodological level used for statistical data collection and processing in Russia. On the basis of data listed above, there was a list of indicators (2014) formed for a special inquiry to the Tomsk Regional Statistics Service (Tomskstat). The inquiry included data indicators starting from the year of 2000, since it was necessary to compare different time periods in terms of country's economic growth and development including both relatively prosperous and disadvantaged years.

Selection process of relevant objective indicators integrated the study of the following statistical monitoring forms: "Minimum subsistence level costs in the regions of the Russian Federation", "On the social support implementation measures for certain categories of citizens subsidies from the consolidated budget of the Russian Federation", "On the number of employees and their wages in social services system by categories of personnel", "On the incoming and allocated payments of the Pension Fund of the Russian Federation", "On the number of pensioners and assigned pension amounts" and other forms incorporating the data on the well-being of the elderly population.

The Table 1 shows the time period (depth) during which the data for the section "Older generation" of the FSSS on the federal level was collected. According to this information, we can assess the wellbeing of the elderly population with reasonable accuracy using a sufficient amount of data on the indicated issues. The majority of the 65 selected indicators have depth of 3-4 years, which imposes certain limitations for the enhanced dynamics monitoring of the selected indicators for a continued time period. As a comparison, the second column of the Table 1 represents the time depth characteristics of the Tomskstat data collection for 2000-2014. The vast majority of selected indicators can be covered by the collected and processed data for a time period of at least 7 years. The analysis of data during these years allows us to draw the conclusion on the sufficient data accuracy on the chosen object of study such as the well-being of the elderly population in Russia and its regions as well as the object's performance changes.

Table 1. Comparative time depth of data collection on federal and regional levels

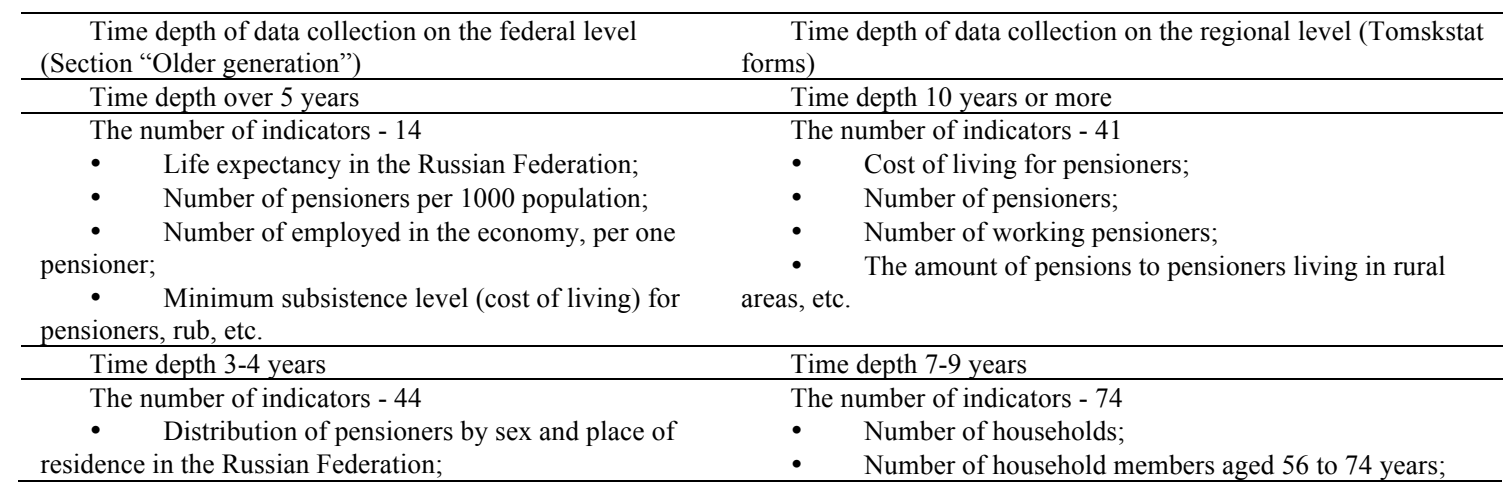




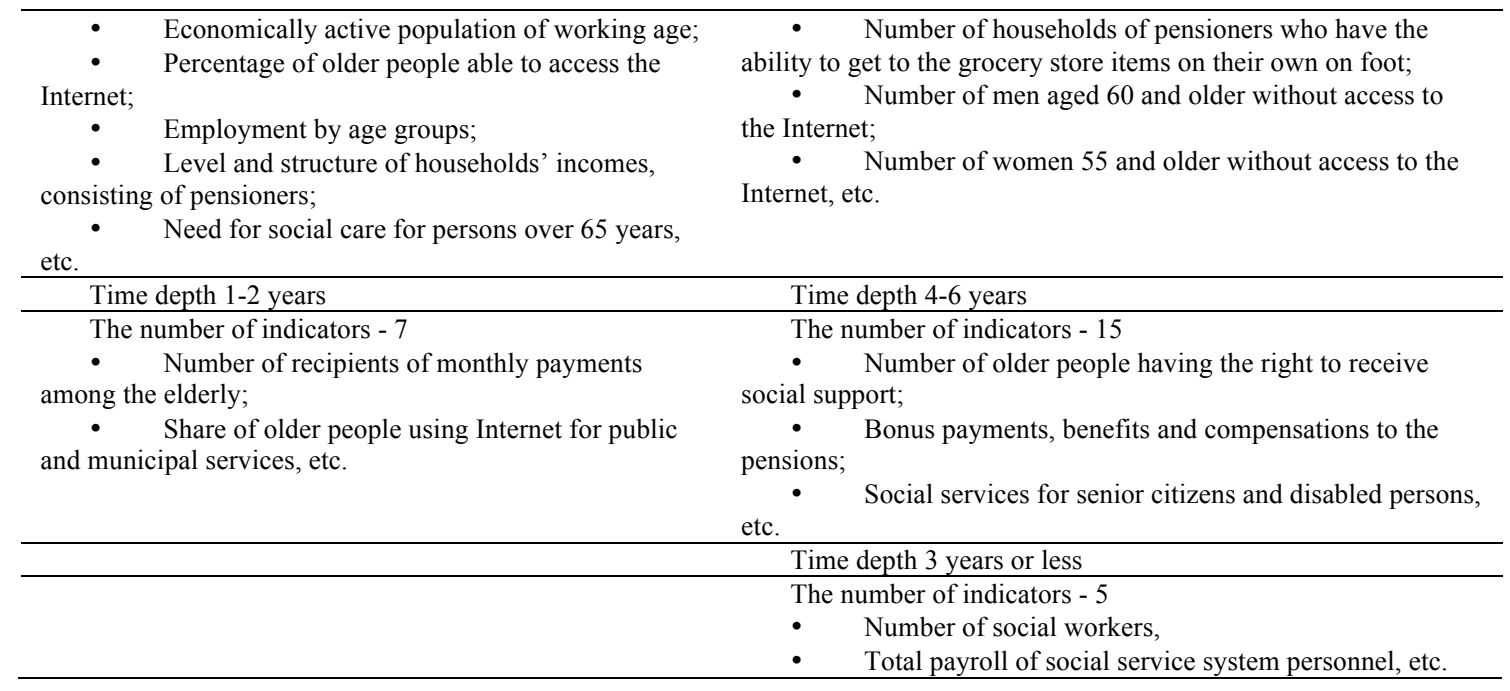

The Figures 1 and 2 illustrate the time depth (time period) of data on the collected and processes indicators for the elderly population well-being evaluation. The vertical axis shows the time period depth, while the horizontal axis is assigned to a list of the selected enumerated indicators.

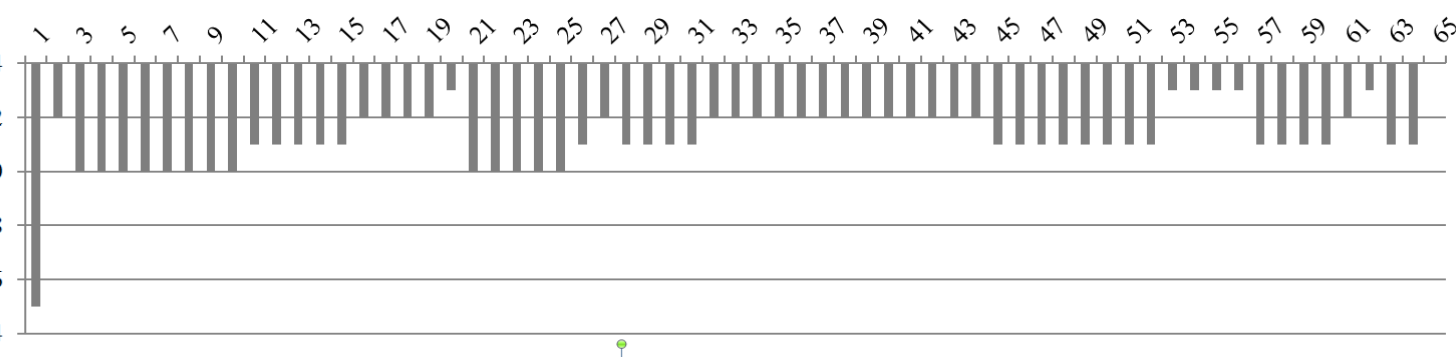

Fig. 1. Time depth of data collection on the federal level (Section "Older generation")

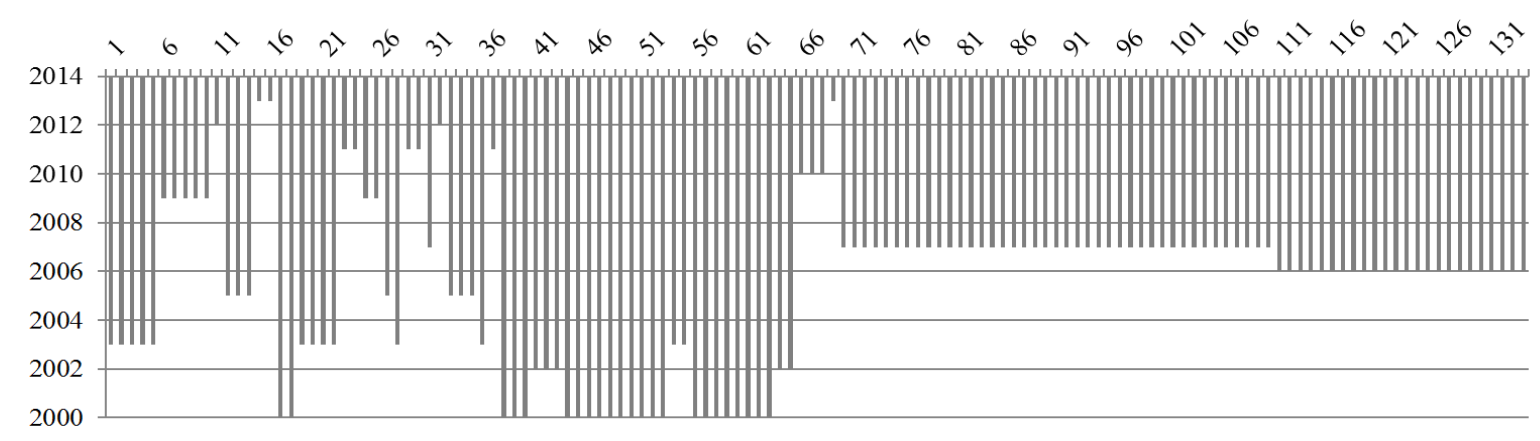

Fig. 2. Time depth on the regional level (Tomskstat) data collection

\section{Discussion}

It is noteworthy that there is a problem from the point of view of the objective indicators development and evaluation of the elderly population well-being in Russia. The country is experiencing a shortage of data on many indicators that are comparable with those of foreign countries. Since the monitoring of the elderly population level of life is relatively recent for Russia, it is still impossible to trace the dynamics for the most of the indicators for the purpose of longitudinal analysis.

Based on selected indicators, we determine the time periods depth, which is required to describe the well-being of the elderly generation with needed accuracy. Then these indicators put together in 
http://dx.doi.org/10.15405/epsbs.2016.02.50

eISSN: 2357-1330 / Corresponding Author: Irina Pavlova,Email: iapav@mail.ru

Selection and peer-review under responsibility of the Organizing Committee of the conference

domains will be used as the basis for computation of social and economic indices of the older generation well-being in Russia.

Comparative analysis of the chosen Russian statistical forms with indicators used for international indices reveals mismatches in the set of indicators. The first mismatch is related to the difference in socio-economic conditions. Secondly, there is a lack of data in Russia's statistics devoted to the wellbeing of the older generation. For the FSSS group of indicators the recommended time periods depth analysis is 4 years (starting from 2011). The Tomskstat time depth for the submitted data on the wellbeing of the older population on the regional level (Tomsk region) can be assessed relatively well on a number of indicators starting from 2007.

In the Tomsk region at the beginning of 2014 we account 224400 people over working age (men 60 years and older, women - 55 years and older). The number increased by 17800 (or $8.6 \%$ increase), compared to 2011. The main reason of this growth is that generation of 50s began to reach retirement age. During this period, the share of the older retired generation in total population of the Tomsk region increased from $19.7 \%$ to $21.0 \%$ (Fig. 3).

According to international criteria, the population of a region is considered to be "old" since the number of the people $65+$ years surpasses $7 \%$ of the total population. In the beginning of 2014 this figure was $11 \%$ (or every ninth resident). An upward trend appears also in increase of the average age. Over the past three years, the average age of the population increased by one year from 37 years to 38 years.

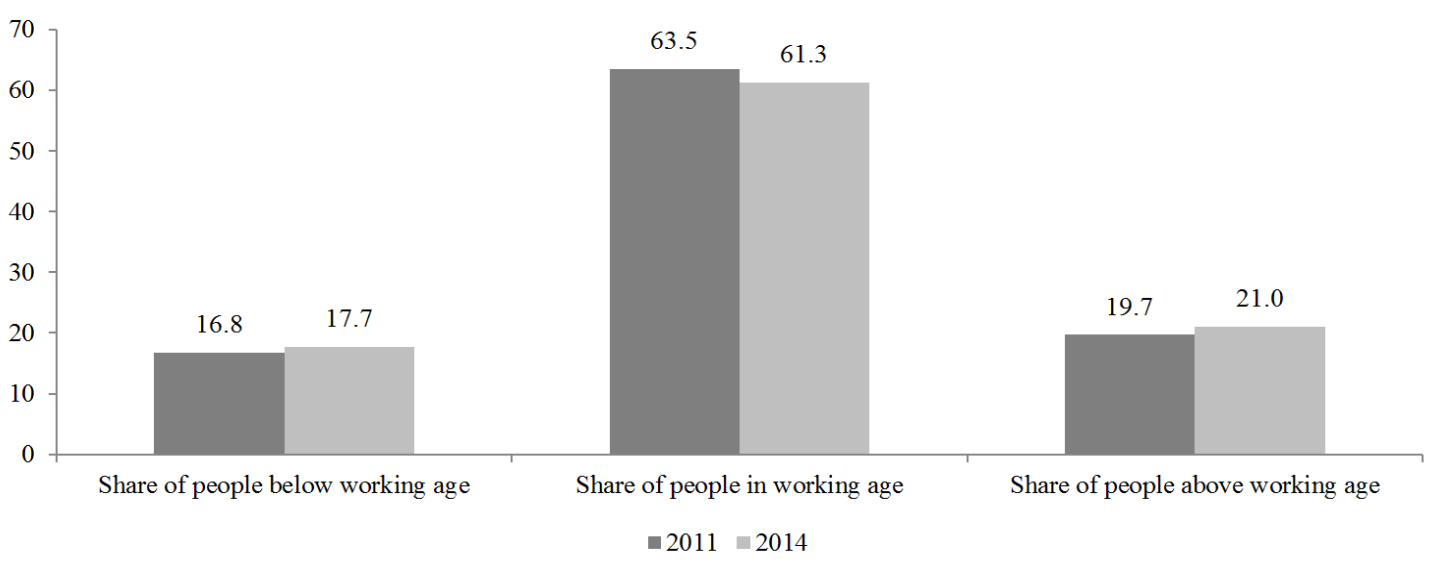

Fig. 3. Share of main age groups in the Tomsk region (\%)

According to the National Population Census 2010, the main source of income of the retired elderly generation is pension. This is true for our region - more than $60 \%$ of the population over working age considers the pension as their main source of income. In addition to pensions, for many pensioners the second major income source is private farming (gardens). Salary as additional full-time or part-time employment holds the third place with $14 \%$ (Fig. 4). Therefore, many people above retirement age continue to work. For example, at the end of 2014, 118800 pensioners ( $48 \%$ of the total number of pensioners) in the region work after reaching the retirement age. This figure can be compared to the number of working pensioners at the end of 2010 , when their share was only $41.8 \%$. In addition, the work for pensioners is not only considered as an opportunity to improve their financial situation, but it represents one of the ways to stay active and be engaged in the society. Thus, every fifth pensioner in 
Tomsk region does not have a family or lives separately from their children, grandchildren or other relatives (National Population Census 2010).

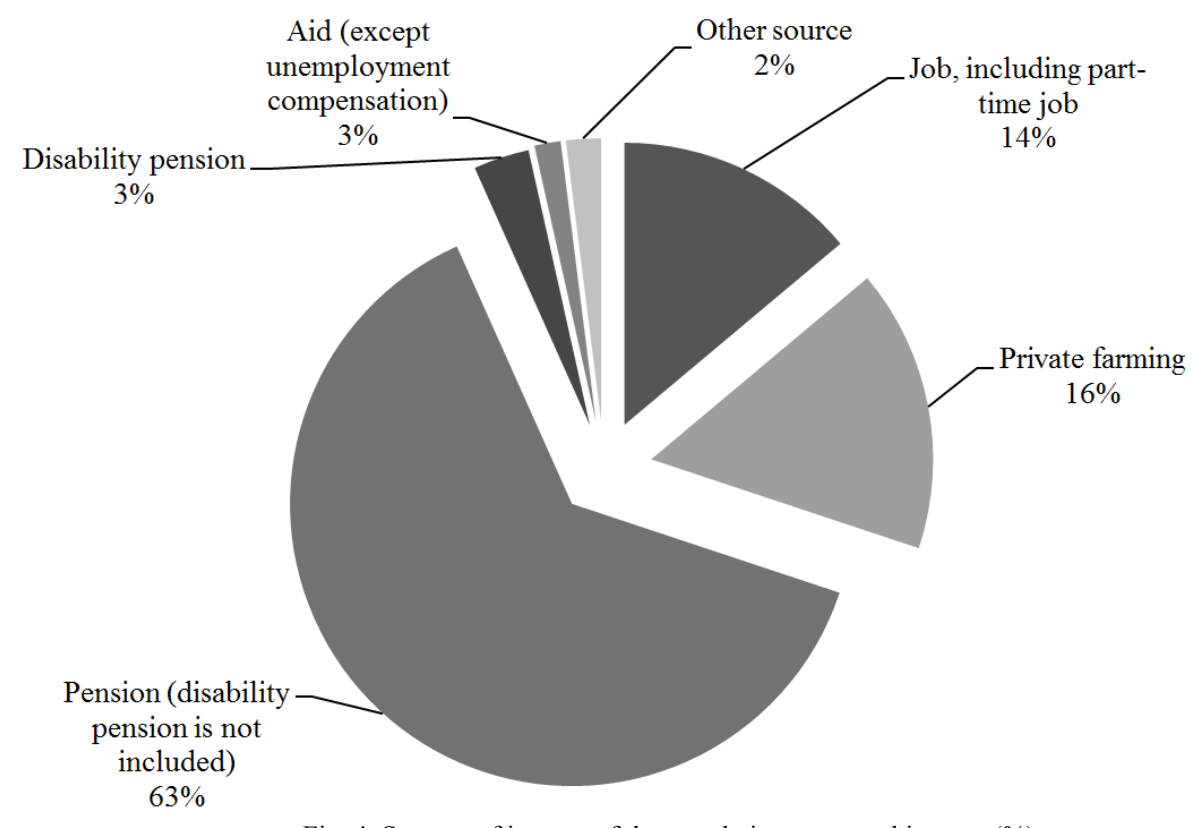

Fig. 4. Sources of income of the population over working age (\%)

Before 2013, annual indexation of pensions by the Government of the Russian Federation contributed to the growth of the real size of monthly pensions. Due to high inflation in 2014, this tendency could not be maintained. Real fixed monthly retirement pension amounted to 94.4\% (Fig. 5). It resulted from the fact that in January 2015 consumer prices for goods and services increased on average by $14.5 \%$ (month-to-month). Most grocery items have risen in price on average by $18 \%$.

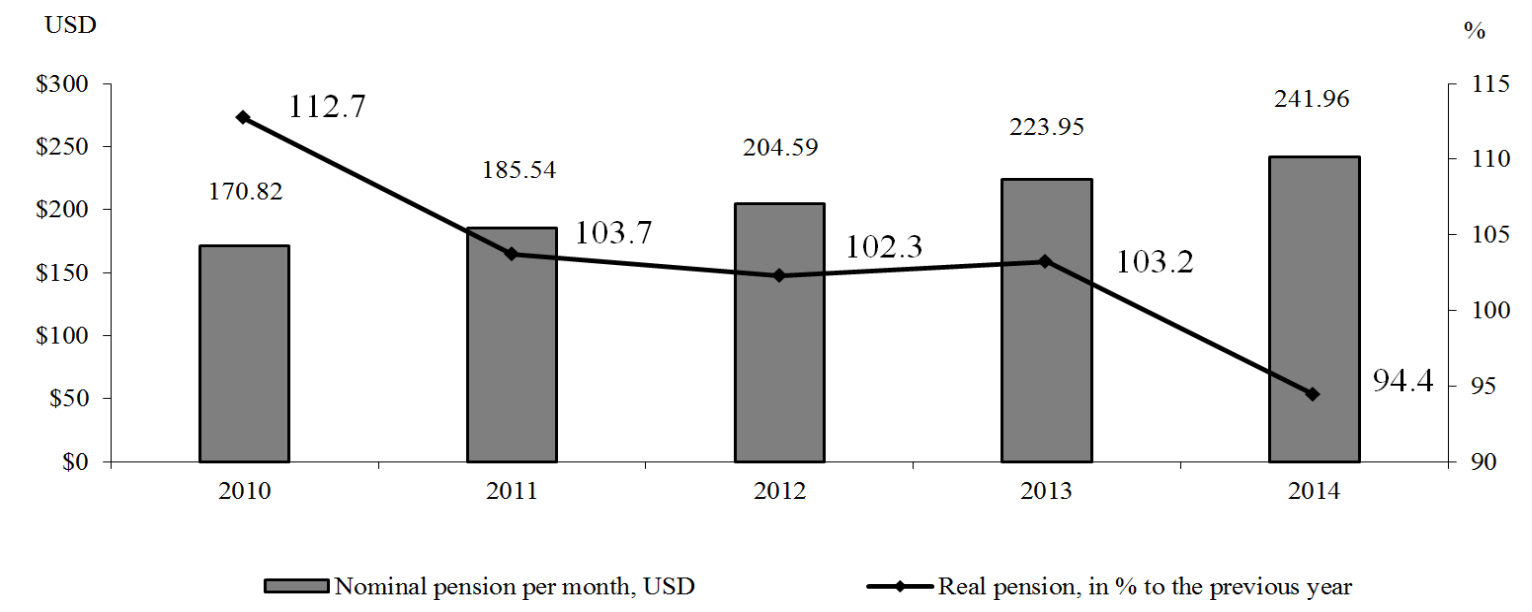

Authors' notes: Real pensions are calculated in real consumer prices. Originally all monthly pensions in Russia are calculated and allocated in Russian rubles. Here the monthly pensions are transferred into the US dollars at the exchange rate established by the Central Bank of the Russian Federation on 30.04.2015 (1 USD=51.70 RUR). The dynamics of the RUR/USD exchange rates are not taken into account. The calculations of monthly pensions are presented in US dollars only for the convenience of the readers.

Fig. 5. Nominal monthly pensions (USD) and dynamics of real pension (\%)

\section{Conclusion}

We consider regional social and economic comparisons in terms of their dynamics as an acute problem on the rise of a new agenda. In previous years, a comparative analysis of the elderly has been 
underdeveloped, so the direction for future research is a very promising comparative study of the older people well-being dynamics in different regions of the Russian Federation. Despite the fact, that new forms for life assessment of the older generation are introduced, this research issues bring up challenging and sensitive problems. At the time, inter-regional comparisons in Russia were mainly associated with the economic situation, whereas socio-economic comparisons were not developed. However, improving quality of life of older people is becoming one of the governmental priorities (On the development of the social security system for senior citizens, 2014). The approaches to the statistical data collection are being reconsidered.

\section{Acknowledgements}

This research was performed by the authors in collaboration with Tomsk Polytechnic University with financial support of the Science and Education Ministry of the Russian Federation within the project in Evaluation and enhancement of social, economic and emotional well-being of older adults under the Agreement No.14.Z50.31.0029.

\section{References}

Federal State Statistics Service: official website. Official documents. URL: http://www.gks.ru/wps/wcm/connect/rosstat main/rosstat/ru/about/credentials (Accessed: 11.12.2014) (in Russian).

Federal State Statistics Service: official website. Forms of federal statistical observation. URL: http://www.gks.ru/metod/forma.html (Accessed: 11.12.2014) (in Russian).

HelpAge International (2014), Global AgeWatch Index 2014: Insight report, summary and methodology. URL: http://www.helpage.org/global-agewatch/reports/global-agewatch-index-2014-insight-report-summary-andmethodology/ (Accessed: 25.11.2014).

HelpAge International (2013), Global AgeWatch Index 2013: Insight report, summary and methodology. URL: http://www.helpage.org/global-agewatch/reports/global-agewatch-index-2013-insight-report-summary-andmethodology/ (Accessed: 25.11.2014)

Zaidi, A., Gasior, K., Hofmarcher, M.M., Lelkes, O., Marin, B., Rodrigues et al. (2013). Active Ageing Index 2012. Concept, Methodology and Final Results. Research Memorandum. Methodology Report, European Centre Vienna, 68 pages.

Federal State Statistics Service: official website. The official statistics. Population. The older generation. URL: http://www.gks.ru/wps/wcm/connect/rosstat main/rosstat/ru/statistics/population/generation/ (Accessed: 10.12.2014) (in Russian).

Federal State Statistics Service: official website. The Table (listing) forms of federal statistical observation. URL: http://www.gks.ru/bgd/free/b15 43/Main.htm (Accessed: 10.12.2014) (in Russian).

Federal State Statistics Service: official website. The album forms of federal statistical observation, data collection and processing which are carried out in the Federal State Statistics Service. URL: http://www.gks.ru/form/index.html Accessed: 10.12.2014) (in Russian).

Federal State Statistics Service: official website. The territorial body of the Federal State Statistics Service in the Tomsk Region. URL: http://tmsk.gks.ru/ (Accessed: 10.12.2014) (in Russian).

The list of instructions following a meeting of the presidium of the State Council of the Russian Federation on the development of the social security system for senior citizens "On the development of the social security system for senior citizens". (2014). (in Russian). 